\title{
Exploring the impact of English-medium instruction on university student academic achievement: The case of accounting
}

\author{
Emma Dafouz \\ English Language and Linguistics, \\ Faculty of Philology \\ María-del-Mar Camacho-Miñano \\ Financial Economics and Accounting II (Accounting) \\ Faculty of Business Administration and Economics \\ Universidad Complutense de Madrid (Spain)
}

\begin{abstract}
As higher education institutions (HEIs) across the world strive to become increasingly international, English-medium instruction (EMI) is swiftly becoming mainstream in contexts where English has traditionally held a foreign language status. This change in the language of instruction has given rise to a number of concerns, which are still largely under-explored. Amongst these, research into the effects of EMI on students' disciplinary knowledge is of great importance and should be regarded as crucial so that HEIs offer the same possibilities for student construction of knowledge, irrespective of the language used.

Our paper duly examines the impact that EMI may have on student academic performance when compared to their counterparts' in their L1 (Spanish). As sample data, a comparable set of first-year student grades was collected for the subject of Financial Accounting I in a Spanish university during four academic years (2010-14). A total of 383 student grades were gathered and compared using mean difference tests. Overall, findings show no statistical differences across groups and that the use of EMI does not lower student final academic outcomes. These results may be relevant for other EMI contexts, the business education community and ESP course developers in general.
\end{abstract}

Keywords: English-medium instruction (EMI), student academic performance, higher education, internationalization at home, assessment, Business studies. 


\section{Introduction}

English-medium instruction (EMI) is swiftly becoming mainstream in Higher Education institutions (HEIs) where English has held by tradition a foreign language status. While the reasons for this are varied (Doiz, Lasagabaster \& Sierra, 2013; FortanetGómez, 2013; Scott, 2011), in Europe the consolidation of the European Higher Education Area (EHEA) has resulted in the use of English as language of instruction as a means to attract both international students and staff, and develop trans-national research and networking. Additionally, the use of English as language of academia, research and the internet remains uncontested, as the growing numbers of publications, journals and conferences in this language clearly show (Mauranen, Hynninen \& Ranta, 2010). In the specific case of Business Studies and given the globalization of the world economy, a high level of competence in English is viewed as a pre-requisite for all business students in the $21^{\text {st }}$ century (Louhiala-Salminen \& Kankaanranta, 2012; Oria, 2012; Taillefer, 2007). Regarding accounting education, the Accounting Education Curriculum (established by the International Federation of Accountants, known as IFAC) claims that mastery of English should be regarded as "general knowledge" that all students should develop (Cole, Branson \& Breesch, 2011; Diaconu, Coman, Gorgan \& Gorgan, 2011; Jeanjean, Lesage \& Stolowy, 2010). On a professional level, companies which adopt English as an external reporting language are associated with a number of benefits related to investors, such as more foreign ownership, less information asymmetry or a reduction in information processing costs (Jeanjean, Stolowy, Erkens \& Yohn, 2014).

Against this generally "Englishized" background, there are, however, important national differences as regards language policies, implementation strategies and teaching traditions, which need to be analysed more carefully. In the specific case of Southern Europe, the spread of EMI instruction may not be as extended as in Central and Northern Europe (see Wächter \& Maiworm, 2014) possibly as a result of the lower levels of English proficiency among university students, lecturers and management in general (Arnó-Macià \& Mancho-Barés, 2015).

Focusing on Spain, where this study is based, national and regional policies to ameliorate from an early age students' low level of English while developing a more international and multilingual and multicultural school population have been implemented since the 2000s. In these so-called 'bilingual schools' children may learn up to $50 \%$ of the subject 
content (history, science, etc.) through a foreign language, which is usually English (Dafouz \& Guerrini, 2009; Lasagabaster \& Ruiz de Zarobe, 2010). In the same way, at the tertiary level, the Spanish Ministry of Education has recently launched an initiative for modernising universities, which seeks for innovation and knowledge transfer on an international level. Under this initiative the Spanish Ministry of Education expects that by 2020 one out of three degree programs be taught through the means of English (see "Strategy for the Internationalization of Spanish Universities", 2014).

In spite of this rapid increase of EMI across different HEIs, limited research has been conducted on the impact that such a phenomenon may have on the teaching and learning of subject matter content through English (but see Dafouz, Camacho \& Urquía, 2014; Tatzl \& Messnarz, 2013). Nevertheless, loss of subject content has often been mentioned as an overt reason for not adopting EMI. Reasons for this lack of research in the area are linked to a number of factors: firstly, the difficulty of setting up interdisciplinary research groups, combining group members and distinct perspectives that go beyond language issues; secondly, the struggle to gain access to students' grades for reasons of confidentiality; thirdly, the non-existence of standardized content exams that enable comparative analyses (Dafouz et al., 2014, p. 224-25) and, finally, maybe "a political or ideological bias, since [as] most researchers are in favour of multilingual education, negative results, especially regarding content achievements, would not benefit the future support of those programmes" (Fortanet-Gómez, 2013, p. 31).

In this light, and given that "the research in relation to content learning is not altogether conclusive" (Ruiz de Zarobe, 2015, p.71), the study presented here aims to fill this important gap by investigating student academic achievement in EMI and non-EMI (Spanish) settings. The study draws on data from 383 first-year students in the subject of Financial Accounting I in English- and Spanish-medium programs taught by the same teacher at the same HEI and across four consecutive academic years (from 2010-14). The subject Financial Accounting I is a basic and compulsory course placed in the second semester for first-year students in the Business Administration Degree. Accounting is a key subject in this degree because it provides essential economic and financial information to the different stakeholders (managers, shareholders, creditors and lenders) so that they make appropriate decisions and run a business effectively (Camacho-Miñano, Akpinar, Rivero, Urquía \& Escola, 2012). In our study, the teacher for both groups is a lecturer with extensive experience teaching this subject, first in Spanish and now also in 
English, and with a great interest in methodology and the use of new technologies in learning.

We believe our study to be innovative in a number of ways: firstly, because it is conducted in a relatively new study context known as internationalization at home (Nilsson, 2003), where most of the students and teachers are learning through an additional language (or L2), which is typically English. This specific setting should not be interpreted in the same light as studies conducted in other HE international contexts where teachers and local students are usually native-speakers and incoming students are non-native speakers. While interesting experiences can be found in these international institutions (traditionally based in English-speaking countries), our particular setting calls for specific research. Secondly, unlike other work which is mostly qualitative, this study follows a quantitative approach and deals with a high number of student results $(\mathrm{N}=383)$ from classrooms where learners have not been placed according to their previous foreign language performance or overall academic grades. The use of such a large sample size, together with the control of other variables such as same setting, subject, and teacher, may help to explore an area which, as was said before, "is not well documented in literature" (Tatzl \& Messnarz, 2013, p. 4).

The paper is structured as follows: the background and extant research to student academic achievement in EMI is shown in section two in order to develop our research questions. In section three the sample is described and the methodology justified. Section four is devoted to the main results and discussion, and finally, the main conclusions and limitations are presented in section five.

\section{Student academic achievement and assessment formats in English-medium instruction}

Student academic achievement and how it is affected by different assessment formats have long been the subject of exhaustive research (Asikainen, Parpala, Virtanen, \& Lindblom-Ylänne, 2013). In European EMI contexts, the inherent complexity of assessing learners is further aggravated by the fact that students are learning a subject in a language that is typically not their L1. As stated in the introduction, research in this domain is neither abundant nor conclusive. There are, nevertheless, a small number of studies (see for example, Kirkgöz, 2005; Sert, 2008 in Turkey; Byun et al., 2011 in Korea) which generally claim that L2 students will have more difficulties in the learning of 
content and thus will obtain lower results, given their non-native speaker status. More specifically, Sert (2008, p. 167) refers to "students' reported uncertainty about their ability to grasp academic content clearly, which might prevent them from developing critical thinking skills". The data in these studies, nevertheless, is very distinct to ours in that they draw on a high number of student questionnaires and teacher interviews to analyse stakeholders' perceptions of the use of English. The focus on perceptions is, in Sert's own words, "the most prominent limitation of the study" since "[he] was not allowed to observe classes and/or analyse documents such as exam papers and assignments for privacy reasons" (Sert, 2008, p. 160). In the Korean study, the EMI policy seems to have produced, in general, positive outcomes as regards the improvement of students' English proficiency. Nevertheless, the compulsory enforcement of EMI, the lack of a muchneeded support system and appropriate instructors, and the unilateral implementation of EMI across academic disciplines have also developed the opinion that EMI "may actually hinder students' acquisition of the subject matter being taught" (Byun et al., 2011, p. 442). Generally speaking, both studies although based in different contexts emphasize the need to revise EMI policies at HEIs to provide more effective learning conditions and support measures for all the stakeholders involved.

In contrast to the above, other research suggests that there is no difference in EMI students' final outcomes when compared to non-EMI learners. In a study of Business students' final grades in three first-year subjects (Economic History, Financial Accounting and Finance) it was found that there were no significant differences among learners and "that both cohorts follow an analogous tendency in all three subjects" (Dafouz et al., 2014, p. 8). This work also suggested that the difficulties students experience in English do not differ greatly from the problems found in L1 lectures, as they are mostly connected to learners' process of developing academic literacy (be it in the students' L1 or L2). Similarly, Hellekjaer (2008, 2010), with a sample of 391 respondents, compared EMI and L1 instruction at three Norwegian HEIs and concluded that there were student lecture comprehension problems in EMI as a result of lecturers' weak pronunciation skills in English. Nevertheless, he also reported that these problems were similarly found in students' L1 as they were connected with the specific language of the disciplines and with the process of "socializing students into domain-specific academic genres and registers with specialized vocabularies" (2010, p. 248). Likewise, Basturkmen and Shackleford (2015) foreground in the particular case of accounting the 
"important role that the learning of fundamental terms and concepts plays in the early stages of developing disciplinary knowledge" (p. 94).

In the most comprehensive of these studies to date, Klaassen (2001) reported that the limiting effects of learning through an L2 on disciplinary content for Dutch engineering students disappeared over the period of a year, when students gradually acquired more disciplinary content and presumably improved their English language competence. Building on Klaassen's work, Airey and Linder (2006) and Airey (2009) stated that in the Swedish EMI settings students often change their learning strategies in a number of ways: reading sections of work before attending lectures or not taking notes in class in order to listen more attentively (see also Tatzl, 2011 for the Austrian context; Vinke, Snippe \& Jochems, 1998 in The Netherlands).

Against this backdrop, our research questions are now formulated in an attempt to cast some light on the conflicting findings that emerge from the diverse implementation of EMI policies. Bearing in mind, as was stated earlier, that most studies questioning students' capacity to learn disciplinary content in another language draw on questionnaire and interview data, our first research question is presented as follows:

RQ1) Does the language of instruction (L2 English or L1 Spanish) have an impact on students' final academic results (i.e. grades)?

We pose this question since closely connected to student final results are the different assessment formats that may be used for evaluation. Student grades can be collected in a variety of formats: oral or written examinations (essay type or multiple choice, long or short answers, problem-solving, or expository essay genres), student coursework (collected throughout the course or only on specific occasions) or portfolios. These different formats may favour the development of certain learning styles and linguistic abilities and, concurrently may be also strongly contingent on students' language skills. In other words, if students are asked to complete multiple-choice exams rather than essaytype exams they will usually develop the skills that match the assessment they are measured by. Likewise, students in an EMI context may be expected to participate less dynamically in the classroom, as a result of their limited oral ability in the L2 and thus will obtain a lower grade in that specific type of assessment. Airey and Linder (2006, p. 555) compared lecture comprehension in English and Swedish and reported that students learning through English were more reluctant to ask and answer questions in class, but rather approached the teacher on an individual basis once the session had concluded. In contrast, the study by Urquía, Camacho-Miñano and Dafouz (under review) analysed the 
different learning strategies that EMI and non-EMI groups enacted in the classroom and concluded that, on the whole, EMI learners adopted a much more participatory role in their learning than the non-EMI counterparts. Active participation included the frequent use of teacher-addressed questions and enactment of a wider range of socio-affective strategies, especially teamwork and pair-work, in order to ensure that their understanding of the complex subject matter was accurate.

Research that directly links students' language of instruction in EMI settings with student achievement in the different assessment formats used is, to our knowledge, practically non-existent. One exception is Dafouz et al. (2014) which analysed students' performance in two types of assessment (coursework and final exam) and concluded that the general tendency for both sets of students (EMI and non-EMI) was to obtain higher results in the coursework than in the final exams. This tendency, however, while consistent in the case of the more quantitative subjects analysed (Financial Accounting and Finance) was not replicated in the case of the more qualitative subject (Economic History). This finding matches some prior literature in HE that claims that in quantitative disciplines coursework grades are usually significantly higher than final exam grades, whereas in qualitative subjects this difference is smaller (Bridges et al., 2002; Murdan, 2005; Simonite, 2003). Whatever the reasons, what seems to be common in tertiary settings (Bridges et al., 2002) is students' lower results in their final exams as these "usually cover extensive material and are more comprehensive whereas coursework breaks up content into smaller units of study that are generally easier to learn" (Dafouz et al., 2014, p.10).

In view of the above, the second research question is formulated as follows: RQ2) Does the use of different assessment formats (i.e. active participation in class, mid-term exam, seminars and final exam) have an effect on students' academic results?

By answering this question, we would like to go deeper into the possible connection that may be found between assessment formats and student achievement and examine whether in certain types of assessment, which initially require more L2 student oral contribution (i.e. active participation and seminars), EMI students obtain different results when compared to their non-EMI counterparts.

Finally, and to complement this analysis, our third research question is formulated as follows: RQ3) Is student distribution in the EMI and non-EMI groups different as regards their academic performance?

With this last question we would like to question with empirical data the belief that EMI cohorts are inherently "selective, so the average ability and motivation [of these students] 
is probably higher in both English and other subjects" (Bruton, 2011, p. 526). It is hoped that the considerable size of our data and the number of different assessment formats analysed will cast some light on this controversial issue.

In the next section, a detailed account of the different assessment formats used in the subject of Financial Accounting I as well as the student distribution by level of academic performance (i.e. high-achievers, medium-achievers and low-achievers) will be provided.

\section{The study}

\subsection{Setting, participants and course subject}

At the School of Economics and Business Administration where this study is based, the EMI courses running since the year 2009 are parallel to their non-EMI equivalents, as both follow the same academic syllabus and use the same types of assessment formats. Students who enrol in the EMI program are required to either certify a B2 level (CEFR) of English in the form of official exams (ESOL or TOEFL), or complete an entry test provided by the School. Additionally, all students in both groups take the same university entrance exam (or 'selectividad') and need to achieve a minimum grade in order to be accepted onto the degree programme. This university entrance exam guarantees as far as it is possible (given the large dataset) the comparability of our sample as regards student general academic aptitude. Upon graduation, an official bilingual certificate is issued by the university to acknowledge student completion of the degree in English.

While our initial sample consisted of 466 students, there were some missing values that were eventually eliminated, as some students did not take any exams nor attend classes regularly. Students repeating the course (18 in EMI and 6 in non-EMI) were also removed from our final data set since these were familiarised with the contents and type of examinations. Likewise, international students (or ERASMUS, 10 in EMI and 7 in nonEMI) were excluded in order to focus on the home students and the internationalization in a home context. Thus, the final sample consists of 383 students (56.9\% male students and $43.1 \%$ female) distributed evenly across the four academic years. By years, in 20102011, 36 students were enrolled in the EMI program and 62 in the non-EMI group; in 2011-12 there were 47 EMI students and 49 non-EMI; in 2012-13 there were 45 students in the EMI group and 52 in the non-EMI, and finally, in 2013-2014, 47 students were 
enrolled in the EMI group and 45 in the non-EMI. Summarising, a total of 175 students (45.7\%) belong to the EMI group and $208(54.3 \%)$ to the non-EMI.

As mentioned in the introduction, the teacher for both groups has more than 10 years' experience in the teaching of Financial Accounting I in Spanish and 6 years in English, and has published extensively in both languages in international academic journals. She is also the coordinator of two manuals ${ }^{1}$ on the subject of accounting used as course textbooks in the EMI and non-EMI groups respectively. A working definition of accounting is "the process of identifying, measuring and communicating financial information about an entity to permit informed judgements and decisions by users of the information"" (Camacho et al., 2012, p. 29). This course is instrumental in understanding the basic principles of other subjects in the BA degree such as Finance, Management, Marketing and Financial Statement Analysis. Like all other academic disciplines, accounting has a specific terminology that students need to master in order to become fully socialised into the subject, first, and the profession, later. The study by Basturkmen and Shackleford (2015) on language-related episodes in first year accounting lectures underlines this idea by stating "that being able to use special purposes vocabulary demonstrates group belonging" (p. 88). In essence then, all students in accounting should "learn a new language": the language of accounting, which encompasses not only vocabulary for special purposes but also four categories of language, namely, grammar, lexis, discourse and accounting register (Basturkmen \& Shackleford, 2015, p. 91; Fortune $\&$ Thorp, 2001). We will return to these matters in section four when our findings are presented and discussed.

\subsection{Data and statistical analysis}

In the context under scrutiny, students' final grades are measured on a 10-point grading scale $^{2}$. Final grades are, in turn, made up of four different components with different weightings: $10 \%$ accounts for student active participation in class, $10 \%$ for the mid-term exam, $20 \%$ for seminars and $60 \%$ for the final exam. By components and as established within the department, active participation accounts for students' preparation of classroom discussions based on the content covered in each chapter and the completion of different tests, exercises or case-studies. Seminars consist of one-hour sessions every fortnight with the whole group divided in two smaller groups, so that the teacher-student ratio is lower (approximately 30 students) and the sessions are more interactive. These 
seminars are designed as problem-based learning sessions, which expose students to case studies, real company situations, and use accounting software and videos from different working professionals. They also encourage students to work in groups and give oral presentations as well as produce individual written assignments. These assignments are submitted during class time and then uploaded on an e-learning platform for teacher online assessment (see Camacho-Miñano, Urquía \& Pascual (2012) for a detailed account of course assessment). Regarding the mid-term and final exam, the content and format are the same in both cohorts (EMI and non-EMI) with two short theoretical questions worth $30 \%$ and a longer problem-based exercise worth $70 \%$. Both exams are completed during class time, are closed-book and timed (two hours approximately).

Concerning student distribution according to level of performance, the EMI and non-EMI cohorts were divided, in turn, into three groups (high-achievers, medium-achievers and low-achievers) on the basis of the final grades obtained for the whole course. Lowachievers are students whose final grades range between 0 and 4.99, medium-achievers are students whose final grades range between 5 and 6.99, and high-achievers are those whose grades range between 7 and 10 .

This set of student data was analysed first descriptively by calculating mean scores, standard deviations, and percentages using SPSS 22. T-tests were conducted to establish differences in means between groups as regards student final grades and different assessment components. Normality and equal variances assumption tests were also carried out. Additionally, ANOVA is used when differences between more than two factors are analysed.

\section{Findings and discussion}

The findings of this study will be presented in accordance with the three research questions formulated. Thus, we will begin by focusing on the results regarding student final grades and then move on to findings related to the four different assessment formats used and the student distribution depending on their level of performance.

\subsection{Student final results}


By and large, the quantitative comparison shows that the final grade on the standardised 10-point grading scale is higher in the EMI groups than in the non-EMI groups (5.17 vs. 4.80). To examine whether these results are statistically different, independent t-tests were employed. The assumption when using t-tests is that the data is normally distributed (Woodrow, 2014). In this case, our data is normally distributed as shown in the Kolmogorov-Smirnov test. A further assumption when using t-tests is that samples need to have equal variance. The test for homogeneity of variance, known as Levene's test of equality of variance, shows that the p-value test is 0.084 , that is, higher than 0.05 . Table 1 displays all these results.

Table 1 here

By and large, non-significant differences were found in the final grades of both EMI and non-EMI students because the p-value, assuming equal variances $(0.127)$, is higher than 0.05. Drawing on this initial result, we can answer the first research question and state that the language of instruction does not seem to have an impact on students' final grades for Financial Accounting I. Analysing further this first result, we examined student final grades by each of the four academic years available (i.e. from 2010 to 2014) as shown in Table 2.

Table 2 here

The findings reveal that EMI students perform slightly better than the non-EMI in three of the four academic years (2010-2011, 2012-2013 and 2013-14). These differences, however, are not statistically significant. The difference is significant, nevertheless, in the case of the academic year 2011-2012, as the p-value is lower than 0.05 ( $p$-value $=0.002$ ). While there is no obvious explanation for this result, which breaks the general trend of the other three years, it is true that the non-EMI cohort for the year 2011-12 was formed by students which enrolled last in the degree. In the Spanish university system ${ }^{3}$, this usually means that these students have a slightly different profile than students that enrolled first, in that they typically obtained a lower score in the university entrance exam. Additionally, they may not have chosen Business Administration as their first option to study at university, hence their later enrolment in the degree. Further studies should look 
into other sets of data to supplement this research in order to draw more conclusive findings.

\subsection{Student academic results by assessment formats}

As regards research question 2, when focusing on the four different assessment formats analysed the trend is that, on average, grades are higher for EMI groups in three of the components (mid-term exam, seminars and final exam), but not in the active participation grade. The total number of students in EMI and non-EMI groups and the mean grades obtained for each of the four assessment components (i.e. mid-term exam, active participation, seminars and final exam) are shown in Table 3.

Table 3 here

An independent sample t-test was conducted to determine whether there were significant differences in the grades of the two groups. Results show that there are no statistically significant differences in any of the components analysed (p-values are higher or equal than 0.05). These findings address our second research question in that the use of different assessment formats does not seem to have an impact on students' performance, whether in EMI or non-EMI cohorts.

The similarities across groups, both on a general level (student final grades) and a more specific level (student results by assessment formats) could be linked to a number of factors. One possible interpretation may be related to students' learning in an internationalization at home context. In this setting, although they are examined in an L2 (English), the examination criteria implemented and the assessment formats they are measured by have not changed. In contrast to what often happens when studying abroad in international HEIs, these students do not have to adjust to the different principles of another educational culture (see Benzie, 2010). These principles, typically implicit, are often agglutinated under the term "academic acculturation" and can be loosely described as the "predominant values, assumptions and behaviours" that operate within a specific setting and academic discipline (van de Poel \& Gasiorek, 2012, p. 59) and that are essential for students to integrate successfully in the academic community. Although most stakeholders (whether teachers or students) agree that differences in educational (or 
academic) cultures do exist, what this actually covers is still unclear to many and certainly goes beyond the scope of this paper. However, in our particular case, as both EMI and non-EMI students are familiar with the assessment formats and the academic and cultural conventions that operate in this specific university, this might explain why there may be no significant differences among the two groups of students analysed.

Another possible interpretation for the similarity of our results could be connected with the nature of the discipline under scrutiny. Accounting is usually classified as a soft/applied discipline (see Biglan, 1973). However, within the actual degree of Business Administration and Economics, and when compared to other subjects, such as marketing or economic history, accounting stands on the "harder" end of the continuum as it deals with numerical and quantitative data. From a linguistic point of view (whether L1 or L2), this subject would typically demand relatively less language production on the part of the students than reception, through the reading of the textbook and listening to the teacher's explanations (Becher \& Trowler, 2001; Dafouz et al., 2014). This would explain initially why some first-year students' limited competence in the L2 may not be a critical issue in passing this subject, given the assessment formats used (mostly problem-solving exercises $)^{4}$. At the same time, as was mentioned before, the language of this discipline is "foreign" to all learners (whether EMI or non-EMI), as they have not been exposed to this specific terminology before. Thus, entry to HE involves a process of "academic discourse socialization" (Duff, 2004) or development of "academic literacy" (Street, 2005), whereby learners "need to engage in a variety of practices in their particular discipline, often switching between different genres and academic practices" (Benzie, 2010, p. 453). Regarding specific vocabulary, the Financial Accounting teacher herself explained that the EMI group usually found it easier to learn the English terminology than the non-EMI group did in their L1 (Spanish), as the former had not been "contaminated" with a non-technical use of the terms. This fact was illustrated with specific examples from accounting lexis in English and Spanish. For instance, the term 'account receivables' in English refers to the right to collect money when a company sells its products. However, in Spanish students tend to use the term 'clientes' (i.e. customers) in a general, non-specialised sense rather than in the disciplinary sense when specifically referring to 'account receivables'. This confusion in the terminology (and often inaccurate use) is more often found amongst the non-EMI students than the EMI. Similarly, Moreno Alemany (2008), claims that the non-EMI students in his accounting classrooms experience more difficulties with the ESP vocabulary than EMI students, as they need to 
realize that "a technical word in accounting cannot be directly translated from Spanish to English because it could result in a false cognate" $(2008$, p. 28$)$.

\subsection{Student distribution and results by level of performance}

Interestingly, the distribution of our students in the three different groups is similar in EMI and non-EMI groups, as Table 4 shows. The percentage of medium and high achievers are very similar in EMI (19.1\% and $12.3 \%)$ versus non-EMI groups $(20.1 \%$ and $12.5 \%$ ). There is a slight difference in the low-achievers, being $14.4 \%$ in the EMI groups versus $21.7 \%$ in the non-EMI groups. Perhaps this higher percentage of low-achievers over the total sample could explain why EMI students obtain, on average, slightly better results than the non-EMI.

Table 4 here

To analyse the differences between the levels of achievement in Table 5, an ANOVA test was used as there were three groups to compare. The three groups of students obtained similar results in the final grade, none of which are statistically significant (as all the pvalues of ANOVA are higher than 0.05). This suggests that low-achievers, mediumachievers and high-achievers behave in a similar way, irrespective of the language of instruction used (whether English or Spanish).

Table 5 here

Focusing on the four assessment formats, there are, however, some differences between the three groups surveyed. As regards low-achievers, there is only one statistically significant difference between groups and that involves the active participation grade (10\% of final grade). In this respect, the non-EMI group obtained higher marks in active participation than the EMI (3.24 vs. 1.78). Having taught EMI groups for 6 years and non-EMI groups (Spanish) for 10, the content teacher claimed that, generally speaking, low-achievers in both groups usually obtain a low grade in this component as they participate less in classroom discussions, often fail to submit homework exercises, and do not always complete practical exercises on the blackboard when requested. As all these activities are included in the active participation grade, it is not surprising that overall 
low-achievers obtain poorer results than the other two sub-groups (medium and highachievers) as seen in Table 5. What remains to be analysed is whether the EMI groups' weaker results in this particular component may be related to comparatively lower English-language skills (than medium and high-achievers) or to other non-linguistic matters. In this regard, the content teacher declared that lower scores across groups are sometimes connected to lower levels of student motivation in the course, rather than to lower proficiency in English (as all EMI students are required to attain a B2 level before commencing the degree). She even maintained that some low-achievers have better English language skills than the high-achievers' cohort. Further research, which is beyond the scope of this paper, should look into these matters.

Concerning the medium-achievers, despite results showing slight differences in the final grades obtained by EMI and non-EMI students, these are not statistically significant. Generally speaking, as reflected in Table 5, most students perform rather weakly in their mid-term exam, as they are gradually becoming acculturated into the discipline and its highly specific terminology. Consequently, grades are largely low in both cohorts (EMI and non-EMI) with results steadily improving as students become more familiar with both the content and language of the subject. Finally, in the seminars both groups obtained the same results (7.0).

Regarding the high-achievers, findings reveal that these sub-groups perform alike in the four assessment formats analysed, to the point that in the final grade the means are very close (7.68 vs. 7.72 ). Non-EMI groups, however, show slightly higher results in all the components of the final grade except in seminars, although, as Table 5 displays, none of these differences are statistically significant. Such findings call for a qualitative analysis of the actual instructional practices and formative assessment (see Camacho-Miñano et al. under review) implemented in these classrooms that would come to supplement this quantitative research.

\section{Conclusions}

The study presented here aimed to investigate an area of EMI research that has been largely under-explored, namely student academic achievement. The use of a set of data from two student groups (EMI and non-EMI), based in the same university setting, learning the same academic subject, with the same teacher and following the same range of assessment formats, makes this study comparable. Our main finding reveals that EMI 
students in the subject of Financial Accounting I obtain the same academic results as their non-EMI counterparts, regardless of the language of instruction used (Spanish or English). This outcome questions earlier studies that assume that learning content through an L2 will automatically lower student academic results.

Additionally, our work went on to discern whether differences between EMI and nonEMI groups could be found in relation to the types of assessment formats used (i.e. midterm and final exams, seminar assignments and student active participation). This analysis aimed to establish whether there could be a relationship between students' English language proficiency and the language demands of the aforementioned assessment formats used. Again, no significant differences were found between the groups, with students performing in a very similar manner.

Finally, student academic distribution and performance were also taken into consideration, in order to verify whether the most competent students, academically speaking, usually belong to the EMI groups. To this end, student results were divided into three groups (high-achievers, medium-achievers and low-achievers) depending on their final academic results by assessment formats. In this regard, there was only one assessment format, namely active participation, which proved to be statistically significant between the lower-achievers in the EMI and non-EMI groups. All other factors behaved in the same way across both student cohorts.

With this study, drawing on a significant amount of student data ( $N=383$ students), our research has attempted to shed some light on a research focus in EMI which has, to date, produced contradictory and inconclusive results. Although the specificity of the context, reduced to one single setting (a Spanish university), and the discipline under scrutiny (accounting) are obvious limitations to this study, we believe that the size of the sample and the comparable nature of the data set analysed (i.e. the same instructor teaching the same subject at the same university) makes the research valid. Further replication across other HEIs by those with access to relevant data, and maybe adopting a longitudinal perspective on student academic performance over time, will add to the accumulating knowledge about the relationship between EMI and student achievement in business degrees and enable more confident generalisations beyond specific institutions.

Finally, our results support the belief that the EMI/non-EMI factor, at least in the specific context analysed, does not necessarily entail different results in student academic achievement. As our findings show, the EMI students surveyed are not only performing at the same level as their non-EMI counterparts but, in addition, are developing the 
specific disciplinary literacy in English to study and communicate in this language and to eventually be able to study and/or work in an international context if they so wish or need.

\section{Acknowledgements}

We would like to thank the anonymous reviewers who offered constructive comments on earlier drafts of this paper and to Dr Cristina del Campo for her assistance with the statistical analyses. This work is part of the INTE-R-LICA project (www.ucm.es/interlica) which is funded by the Spanish Ministry of Education and Competitiveness (FFI2013-41235-R).

\section{References}

Airey, J., \& Linder, C. (2006). Language and the experience of learning university physics in Sweden. European Journal of Physics, 27(3), 553-560.

Airey, J. (2009). Science, Language and Literacy. Case Studies of Learning in Swedish University Physics. Acta Universitatis Upsaliensis. Uppsala Ph.D. Dissertations. Uppsala, Finland: Faculty of Science and Technology.

Arnó-Macià, E., \& Mancho-Barés, G. (2015). The role of content and language in content and language integrated learning (CLIL) at university: Challenges and implications for ESP. English for Specific Purposes, 37(1), 63-73

Asikainen, H., Parpala, A., Virtanen, V., \& Lindblom-Ylänne, S. (2013). The relationship between student learning process, study success and the nature of assessment: A qualitative study. Studies in Educational Evaluation, 39(4), 211-217.

Barwell, R. (2009). Researchers' descriptions and the construction of mathematical thinking. Educational Studies in Mathematics, 72(2), 255-269.

Basturkmen, H., \& Shackleford, N. (2015). How content lecturers help students with language: An observational study of language-related episodes in interaction in first year accounting classrooms. English for Specific Purposes, 37(1), 87-97.

Becher, T., \& Trowler, P. R. (2001). Academic tribes and territories (2nd ed.). Buckingham, England: Society for Research into Higher Education \& Open University Press.

Benzie, H. J. (2010). Graduating as a 'native speaker': International students and English language proficiency in higher education. Higher Education Research \& Development, 29(4), 447-459.

Biglan, A. (1973). The characteristics of subject matter in different academic areas. Journal of Applied Psychology, 57(3), 195-203. 
Bridges, P., Cooper, A., Evanson, P., Haines, C., Jenkins, D., Scurry, D., Woolf, H., \& Yorke, M. (2002). Coursework marks high, examination marks low: discuss. Assessment and Evaluation in Higher Education, 27(1), 35-48.

Bruton, A. (2011). Is CLIL so beneficial, or just selective? Re-evaluating some of the research. System, 39(4), 523-532.

Byun, K., Chu, H., Kim, M., Park, I., Kim, S., \& Jung, J. (2011). English-medium teaching in Korean higher education: Policy debates and reality. High Education, 62(4), 431- 449.

Camacho-Miñano, M.M. \& Rivero Menéndez, M.J. (2010). Introducción a la contabilidad financiera. Madrid, Spain: Ed. Pearson (Spanish version).

Camacho-Miñano, M.M.; Urquía, E. \& Pascual, D. (2012). Seminarios activos: un recurso para motivar al alumnado universitario al estudio de la Contabilidad. "Active seminars: A pedagogical resource to motivate students" Educade: Revista de Educación en Contabilidad, Finanzas y Administración de Empresas, 3, 95-110.

Camacho-Miñano, M.M.; Akpinar, M.; Rivero, M.J.; Urquía, E. \& Eskola, A. (2012). Beyond figures: Introduction to Financial accounting. Madrid, Spain: Anaya (English version).

Camacho-Miñano, M.M.; del Campo, C.; Pascual-Ezama, D.; Rivero, C.; Urquía Grande, E. \& Akpinar, M. (under review) A study of the factors influencing assessment methodologies.

Cole, V., Branson, J., \& Breesch, D. (2011). The illusion of comparable European IFRS financial statement. Beliefs of auditors, analysts and other users. Accounting and Management Information System, 10(2), 106-134.

Dafouz, E., \& Guerrini, M. C. (2009). CLIL across Educational Levels: Experiences from Primary, Secondary and Tertiary Contexts. London: Richmond Publishing.

Dafouz, E., Camacho, M. \& Urquía, E. (2014). 'Surely they can't do as well': a comparison of business students' academic performance in English-medium and Spanish-as-first-language-medium programmes. Language and Education, 28 (3), 223-236.

Diaconu, P., Coman, N., Gorgan, C., \& Gorgan, V. (2011). The needs of the financial labor market in Romania and the answer of the local universities to this social demand. Accounting and Management Information Systems, 10(1), 55-73. 
Doiz, A., Lasagabaster, D., \& Sierra, J. (2013). Globalisation, internationalisation, multilingualism and linguistic strains in higher education. Studies in Higher Education, 38(9), 1407-1421.

Duff, A. (2004). Understanding academic performance and progression of first-year accounting and business economics undergraduates: the role of approaches to learning and prior academic achievement. Accounting Education, 13(4), 409-430.

Fortanet-Gómez, I. (2013). CLIL in Higher Education: Towards a Multilingual Language Policy. Bristol, England: Multilingual Matters.

Fortune, A., \& Thorp, D. (2001). Knotted and entangled: New light on the identification, classification and value of language related episodes in collaborative output tasks. Language Awareness, 10(2-3), 143-160.

Hellekjaer, G.O. (2008). A case for improved reading instruction for academic English reading proficiency. Acta Didactica Norge, 2(1), Art-3.

Hellekjaer, G.O. (2010). Language Matters Assessing Lecture Comprehension in Norwegian English-Medium Higher Education. In C. Dalton-Puffer, T. Nikula \& Smit (Eds.) Language Use in Content-And-Language-Integrated Learning (CLIL) (pp. 233-258). Amsterdam, Netherland: John Benjamins.

Jeanjean, T., Stolowy, H., Erkens, M., \& Yohn, T. L. (2014). International evidence on the impact of adopting English as an external reporting language. Journal of International Business Studies, 46(4), 180-205.

Jeanjean, T., Lesage, C., \& Stolowy, H. (2010). Why do you speak English (in your annual report)? The International Journal of Accounting, 45(2), 200-223.

Kirkgöz, Y. (2005). English language teaching in Turkey: Challenges for the 21st Century. In Braine, G. (ed.) Teaching English to the world: History, curriculum, and practice, (pp. 159-175). New York, USA: Routledge.

Klaassen, R. (2001). The international university curriculum: Challenges in Englishmedium engineering education. Doctoral Thesis, Department of Communication and Education, Delft, Netherland: Delft University of Technology.

Lasagabaster, D., \& Y. Ruiz de Zarobe, (eds.) (2010). CLIL in Spain: Implementation, Results and Teacher Training. Newcastle upon Tyne, England: Cambridge Scholars Publishing.

Louhiala-Salminen, L., \& Kankaanranta, A. (2012). Language as an issue in international internal communication: English or local language? If English, what English? Public Relations Review, 38(2), 262-269. 
Mauranen, A., Hynninen, N., \& Ranta, E. (2010). English as an academic lingua franca: The ELFA project. English for Specific Purposes, 29(3), 183-190.

Moreno Alemany, P. (2008). English Content-Based Approaches to Teaching Accounting. Latin American Journal of Content \& Language Integrated Learning, $1(1), 26-34$.

Murdan, S. (2005). Exploring relationships between coursework and examination marks: a study from one school of pharmacy. Pharmacy Education, 5(2), 97-104.

Nilsson, B. (2003). Internationalisation at home from a Swedish perspective: The case of Malmö. Journal of Studies in International Education, 7(1), 27-40.

Oria, B. (2012). Enhancing higher education students' employability: A Spanish case study. International Journal of Technology Management \& Sustainable Development, 11(3), 217-230.

Ruiz de Zarobe, Y. (2015) The Effects of Implementing CLIL in Education. In JuanGarau, M. \& Salazar-Noguera, J. (Eds.): Content-Based Language Learning in Multilingual Educational Environments. (pp.51-68). Switzerland: Springer International Publishing.

Scott, P. (2011). The university as a global institution. In R. King, S. Marginson, \& R. Naidoo (Eds.). The Handbook of Globalisation and Higher Education (pp. 59-75) Cheltenham, England: Edward Elgar.

Sert, N. (2008). The language of instruction dilemma in the Turkish context. System, 36(2), 156-171.

Simonite, V. (2003). The impact of coursework on degree classifications and the performance of individual students. Assessment and Evaluation in Higher Education, 28(5), 459-470.

Spanish Ministry of Education (2014). Strategy for the Internationalization of Spanish Universities. Retrieved from http://www.mecd.gob.es/educacion$\underline{\mathrm{mecd} / \mathrm{dms} / \mathrm{mecd} / \mathrm{educacion}-\mathrm{mecd} / \text { areas-educacion/universidades/politica- }}$ internacional/estrategia-internacionalizacion/EstrategiaInternacionalizaci-nENGLISH.pdf

Street, B. V. (2005). At last: Recent applications of new literacy studies in educational contexts. Research in the Teaching of English, 39(4), 417-423.

Taillefer, G. F. (2007). The professional language needs of Economics graduates: Assessment and perspectives in the French context. English for Specific Purposes, 26(2), 135-155. 
Tatzl, D. (2011). English-medium masters' programmes at an Austrian university of applied sciences: Attitudes, experiences and challenges. Journal of English for Academic Purposes, 10(4), 252-270.

Tatzl, D., \& Messnarz, B. (2013). Testing foreign language impact on engineering students' scientific problem-solving performance. European Journal of Engineering Education, 38(6), 620-630.

Urquía, E., Camacho-Miñano, M.M. \& Dafouz, E. (under review). A comparative analysis of students' learning strategies in bilingual and non-bilingual degrees: Towards a new classroom dynamics?

Van de Poel, K., \& Gasiorek, J. (2012). Academic acculturation: The case of writing in an EFL teaching and learning environment. Journal for Language Teaching, 46(2), $58-72$

Vinke, A. A., Snippe, J., \& Jochems, W. (1998). English medium Content Courses in Non English Higher Education: A study of lecturer experiences and teaching behaviours. Teaching in Higher Education, 3(3), 383-394.

Wächter, B. \& Maiworm, F. (Eds.). (2014) English-Taught Programmes in European Higher Education: The State of Play in 2014. Bonn, Germany: Lemmens.

Woodrow, L. (2014). Writing about Quantitative Research in Applied Linguistics. New York, USA: Palgrave Macmillan. 
Table 1. Independent samples T-test for EMI and non-EMI final grades

\begin{tabular}{|c|c|c|c|c|c|c|c|c|c|c|c|c|c|}
\hline \multirow{3}{*}{\multicolumn{2}{|c|}{ SD }} & \multirow{3}{*}{1} & \multirow{3}{*}{ M } & \multicolumn{5}{|c|}{$\begin{array}{l}\text { Levene's } \\
\text { Test for } \\
\text { Equality } \\
\text { of } \\
\text { Variances }\end{array}$} & \multicolumn{5}{|c|}{ t-test for Equality of Means } \\
\hline & & & & \multirow{2}{*}{4} & \multirow[b]{2}{*}{$\mathrm{F}$} & \multirow[b]{2}{*}{ Sig } & \multirow[b]{2}{*}{$\mathrm{t}$} & \multirow[b]{2}{*}{$\mathrm{df}$} & \multirow{2}{*}{$\begin{array}{l}\text { Sig. } \\
(2- \\
\text { tailed } \\
\quad)\end{array}$} & \multirow{2}{*}{$\begin{array}{c}\text { Mean } \\
\text { Differe } \\
\text { nce }\end{array}$} & \multirow{2}{*}{$\begin{array}{l}\text { Std. } \\
\text { Error } \\
\text { Diffe } \\
\text { rence }\end{array}$} & \multicolumn{2}{|c|}{$\begin{array}{l}95 \% \text { Confidence } \\
\text { Interval of the } \\
\text { Difference }\end{array}$} \\
\hline & & & & & & & & & & & & Lower & Upper \\
\hline \multirow[t]{2}{*}{$\begin{array}{l}\text { FINAL } \\
\text { GRADE }\end{array}$} & $\begin{array}{l}\text { Non- } \\
\text { EMI }\end{array}$ & $\begin{array}{l}208 \\
2.381\end{array}$ & 4.805 & $\begin{array}{c}\text { Equal } \\
\text { variances } \\
\text { assumed }\end{array}$ & $\begin{array}{c}2.99 \\
3\end{array}$ & $\begin{array}{l}0.0 \\
84\end{array}$ & $\begin{array}{c}- \\
1.529\end{array}$ & 381 & 0.127 & $\begin{array}{c}- \\
0.3651 \\
9\end{array}$ & $\begin{array}{c}0.238 \\
86\end{array}$ & $\begin{array}{c}- \\
0.83483\end{array}$ & 0.10446 \\
\hline & $\overline{\text { EMI }}$ & $\begin{array}{l}175 \\
2.264\end{array}$ & 5.171 & $\begin{array}{c}\text { Equal variances } \\
\text { not assumed }\end{array}$ & & & $\begin{array}{c}- \\
1.536\end{array}$ & $\begin{array}{c}375.3 \\
22\end{array}$ & 0.125 & $\begin{array}{c}- \\
0.3651 \\
9\end{array}$ & $\begin{array}{c}0.237 \\
82\end{array}$ & $\begin{array}{c}- \\
0.83281\end{array}$ & 0.10244 \\
\hline
\end{tabular}

Table 2. Independent samples T-test for EMI and non-EMI final grades by academic year

\begin{tabular}{|c|c|c|c|c|c|c|c|c|c|}
\hline $\mathrm{N}$ & GROUP & & $\mathrm{M}$ & SD & $\mathrm{t}$ & df & $\begin{array}{l}\text { Sig. }(2- \\
\text { tailed) }\end{array}$ & $\begin{array}{c}\text { Mean } \\
\text { Difference }\end{array}$ & $\begin{array}{l}\text { Std. Error } \\
\text { Difference }\end{array}$ \\
\hline \multirow[t]{2}{*}{$2010-2011$} & non-EMI & 62 & 4.949 & 2.580 & \multirow{2}{*}{-0.174} & \multirow{2}{*}{88.372} & \multirow{2}{*}{0.862} & \multirow{2}{*}{-0.081} & \multirow{2}{*}{0.466} \\
\hline & EMI & 36 & 5.030 & 1.989 & & & & & \\
\hline \multirow[t]{2}{*}{$2011-2012$} & non-EMI & 49 & 3.942 & 2.378 & \multirow{2}{*}{-3.271} & \multirow{2}{*}{91.114} & \multirow{2}{*}{0.002} & \multirow{2}{*}{-1.435} & \multirow{2}{*}{0.438} \\
\hline & EMI & 47 & 5.378 & 1.903 & & & & & \\
\hline \multirow[t]{2}{*}{$2012-2013$} & non-EMI & 52 & 5.534 & 2.233 & \multirow{2}{*}{0.742} & \multirow{2}{*}{82.298} & \multirow{2}{*}{0.460} & \multirow{2}{*}{0.393} & \multirow{2}{*}{0.530} \\
\hline & EMI & 45 & 5.140 & 2.888 & & & & & \\
\hline \multirow[t]{2}{*}{$2013-2014$} & non-EMI & 45 & 4.706 & 2.000 & \multirow{2}{*}{-0.905} & \multirow{2}{*}{90} & \multirow{2}{*}{0.368} & \multirow{2}{*}{-0.394} & \multirow{2}{*}{0.435} \\
\hline & EMI & 47 & 5.100 & 2.170 & & & & & \\
\hline
\end{tabular}

In bold significant differences (p-value $<0.05$ ).

Table 3. Comparison of EMI and non-EMI grades by assessment components

\begin{tabular}{|c|c|c|c|c|c|c|c|c|c|}
\hline & GROUP & $\mathrm{N}$ & M & SD & $\mathrm{t}$ & df & $\begin{array}{l}\text { Sig. (2- } \\
\text { tailed) }\end{array}$ & $\begin{array}{c}\text { Mean } \\
\text { Difference }\end{array}$ & $\begin{array}{l}\text { Std. Error } \\
\text { Difference }\end{array}$ \\
\hline \multirow[t]{2}{*}{ Mid-term exam (10\%) } & non-EMI & 208 & 3.709 & 2.832 & \multirow{2}{*}{-1.967} & 378.40 & \multirow{2}{*}{0.050} & \multirow{2}{*}{-0.545} & \multirow{2}{*}{0.277} \\
\hline & EMI & 175 & 4.254 & 2.587 & & 5 & & & \\
\hline \multirow[t]{2}{*}{ Active participation (10\%) } & non-EMI & 208 & 5.170 & 2.660 & \multirow{2}{*}{1.310} & 434.49 & \multirow{2}{*}{0.191} & \multirow{2}{*}{0.392} & \multirow{2}{*}{0.299} \\
\hline & EMI & 175 & 4.778 & 3.125 & & 0 & & & \\
\hline \multirow[t]{2}{*}{ Seminars $(20 \%)$} & non-EMI & 208 & 6.078 & 2.732 & \multirow{2}{*}{-1.741} & 380.72 & \multirow{2}{*}{0.083} & \multirow{2}{*}{-0.453} & \multirow{2}{*}{0.260} \\
\hline & EMI & 175 & 6.531 & 2.360 & & 2 & & & \\
\hline \multirow[t]{2}{*}{ Final exam $(60 \%)$} & non-EMI & 208 & 4.503 & 2.723 & \multirow{2}{*}{-1.611} & \multirow{2}{*}{381} & \multirow{2}{*}{0.108} & \multirow{2}{*}{-0.432} & \multirow{2}{*}{0.266} \\
\hline & EMI & 175 & 4.936 & 2.480 & & & & & \\
\hline
\end{tabular}


Table 4. EMI and non-EMI student distribution by level of achievement

\begin{tabular}{c|c|c|c|c|c}
\hline \multirow{2}{*}{ GROUP } & & \multicolumn{3}{|c|}{ GRADE } & Total \\
\cline { 3 - 6 } NON-EMI & LOW & MEDIUM & HIGH & \\
& \% of NON-EMI & 83 & 77 & 48 & 208 \\
& \% of total & $21.7 \%$ & $20.1 \%$ & $23.1 \%$ & $100 \%$ \\
& Count & 55 & 73 & $47 \%$ & $54.3 \%$ \\
\hline EMI & $\%$ of NON-EMI & $31.4 \%$ & $41.7 \%$ & $26.9 \%$ & 175 \\
& \% of total & $14.4 \%$ & $19.1 \%$ & $12.3 \%$ & $45.7 \%$ \\
\hline TOTAL & Count & 138 & 150 & 95 & 383 \\
& $\%$ of total & $36 \%$ & $39.2 \%$ & $24.8 \%$ & $100 \%$ \\
\hline
\end{tabular}


Table 5. Descriptives and differences according to the level of achievement in EMI and non-EMI groups (ANOVA).

\begin{tabular}{|c|c|c|c|c|c|c|c|c|c|c|c|}
\hline GRADE & & & $\mathrm{N}$ & M & SD & & $\begin{array}{l}\text { Sum of } \\
\text { Squares }\end{array}$ & $\mathrm{df}$ & $\begin{array}{l}\text { Mean } \\
\text { S. }\end{array}$ & $\mathrm{F}$ & Sig. \\
\hline \multirow{15}{*}{ LOW } & \multirow{3}{*}{ Mid-term exam } & $\begin{array}{l}\text { Non- } \\
\text { EMI }\end{array}$ & 83 & 1.408 & 1.579 & Between Groups & 2.721 & 1 & 2.721 & \multirow{3}{*}{1.086} & \multirow{3}{*}{0.299} \\
\hline & & EMI & 55 & 1.695 & 1.586 & Within Groups & 340.642 & 136 & 2.505 & & \\
\hline & & Total & 138 & 1.522 & 1.583 & Total & 343.363 & 137 & & & \\
\hline & \multirow{3}{*}{$\begin{array}{l}\text { Active } \\
\text { participation }\end{array}$} & $\begin{array}{l}\text { Non- } \\
\text { EMI }\end{array}$ & 83 & 3.242 & 2.059 & Between Groups & 70.169 & 1 & $\begin{array}{r}70.16 \\
9 \\
\end{array}$ & \multirow{3}{*}{18.747} & \multirow{3}{*}{0.000} \\
\hline & & EMI & 55 & 1.785 & 1.727 & Within Groups & 509.035 & 136 & 3.743 & & \\
\hline & & Total & 138 & 2.661 & 2.056 & Total & 579.204 & 137 & & & \\
\hline & \multirow{3}{*}{ Seminars } & $\begin{array}{l}\text { Non- } \\
\text { EMI }\end{array}$ & 83 & 4.042 & 2.887 & Between Groups & 2.199 & 1 & 2.199 & \multirow{3}{*}{0.284} & \multirow{3}{*}{0.595} \\
\hline & & EMI & 55 & 4.300 & 2.619 & Within Groups & 1054.427 & 136 & 7.753 & & \\
\hline & & Total & 138 & 4.144 & 2.777 & Total & 1056.626 & 137 & & & \\
\hline & \multirow{3}{*}{ Final exam } & $\begin{array}{l}\text { Non- } \\
\text { EMI }\end{array}$ & 83 & 1.715 & 1.614 & Between Groups & 3.495 & 1 & 3.495 & \multirow{3}{*}{1.305} & \multirow{3}{*}{0.255} \\
\hline & & EMI & 55 & 2.040 & 1.669 & Within Groups & 364.197 & 136 & 2.678 & & \\
\hline & & Total & 138 & 1.845 & 1.638 & Total & 367.693 & 137 & & & \\
\hline & \multirow{3}{*}{ Final grade } & $\begin{array}{l}\text { Non- } \\
\text { EMI }\end{array}$ & 83 & 2.302 & 1.281 & Between Groups & 0.556 & 1 & 0.556 & \multirow{3}{*}{0.305} & \multirow{3}{*}{0.582} \\
\hline & & EMI & 55 & 2.432 & 1.446 & Within Groups & 247.748 & 136 & 1.822 & & \\
\hline & & Total & 138 & 2.354 & 1.346 & Total & 248.304 & 137 & & & \\
\hline \multirow{15}{*}{$\begin{array}{l}\text { MEDIU } \\
\text { M }\end{array}$} & \multirow{3}{*}{ Mid-term exam } & $\begin{array}{l}\text { Non- } \\
\text { EMI }\end{array}$ & 77 & 4.306 & 2.133 & Between Groups & 3.136 & 1 & 3.136 & \multirow{3}{*}{0.797} & \multirow{3}{*}{0.374} \\
\hline & & EMI & 73 & 4.595 & 1.813 & Within Groups & 582.529 & 148 & 3.936 & & \\
\hline & & Total & 150 & 4.447 & 1.982 & Total & 585.665 & 149 & & & \\
\hline & \multirow{3}{*}{$\begin{array}{l}\text { Active } \\
\text { participation }\end{array}$} & $\begin{array}{l}\text { Non- } \\
\text { EMI }\end{array}$ & 77 & 5.551 & 2.135 & Between Groups & 0.449 & 1 & 0.449 & \multirow{3}{*}{0.077} & \multirow{3}{*}{0.782} \\
\hline & & EMI & 73 & 5.442 & 2.691 & Within Groups & 868.056 & 148 & 5.865 & & \\
\hline & & Total & 150 & 5.498 & 2.414 & Total & 868.505 & 149 & & & \\
\hline & \multirow{3}{*}{ Seminars } & $\begin{array}{l}\text { Non- } \\
\text { EMI }\end{array}$ & 77 & 7.014 & 1.621 & Between Groups & 0.097 & 1 & 0.097 & & \\
\hline & & EMI & 73 & 7.065 & 1.327 & Within Groups & 326.660 & 148 & 2.207 & 0.044 & 0.834 \\
\hline & & Total & 150 & 7.039 & 1.480 & Total & 326.756 & 149 & & & \\
\hline & & $\begin{array}{l}\text { Non- } \\
\text { EMI }\end{array}$ & 77 & 5.489 & 0.851 & Between Groups & 0.932 & 1 & 0.932 & & \\
\hline & Final exam & EMI & 73 & 5.331 & 0.767 & Within Groups & 97.482 & 148 & 0.659 & 1.416 & 0.236 \\
\hline & & Total & 150 & 5.412 & 0.812 & Total & 98.414 & 149 & & & \\
\hline & & $\begin{array}{l}\text { Non- } \\
\text { EMI }\end{array}$ & 77 & 5.682 & 0.503 & Between Groups & 0.166 & 1 & 0.166 & & \\
\hline & Final grade & EMI & 73 & 5.616 & 0.598 & Within Groups & 45.096 & 148 & 0.305 & 0.544 & 0.462 \\
\hline & & Total & 150 & 5.650 & 0.551 & Total & 45.262 & 149 & & & \\
\hline & & $\begin{array}{l}\text { Non- } \\
\text { EMI } \\
\end{array}$ & 48 & 6.729 & 2.092 & Between Groups & 0.003 & 1 & 0.003 & & \\
\hline & Mid-term exam & EMI & 47 & 6.718 & 1.733 & Within Groups & 344.019 & 93 & 3.699 & 0.001 & 0.979 \\
\hline & & Total & 95 & 6.724 & 1.913 & Total & 344.021 & 94 & & & \\
\hline HIGH & & $\begin{array}{l}\text { Non- } \\
\text { EMI }\end{array}$ & 48 & 7.893 & 1.418 & Between Groups & 9.900 & 1 & 9.900 & & \\
\hline & participation & EMI & 47 & 7.248 & 2.112 & Within Groups & 299.878 & 93 & 3.224 & 3.070 & 0.083 \\
\hline & & Total & 95 & 7.574 & 1.815 & Total & 309.778 & 94 & & & \\
\hline & Seminars & $\begin{array}{l}\text { Non- } \\
\text { EMI }\end{array}$ & 48 & 8.096 & 1.074 & Between Groups & 1.107 & 1 & 1.107 & 1.246 & 0.267 \\
\hline & & EMI & 47 & 8.312 & 0.784 & Within Groups & 82.619 & 93 & 0.888 & & \\
\hline
\end{tabular}




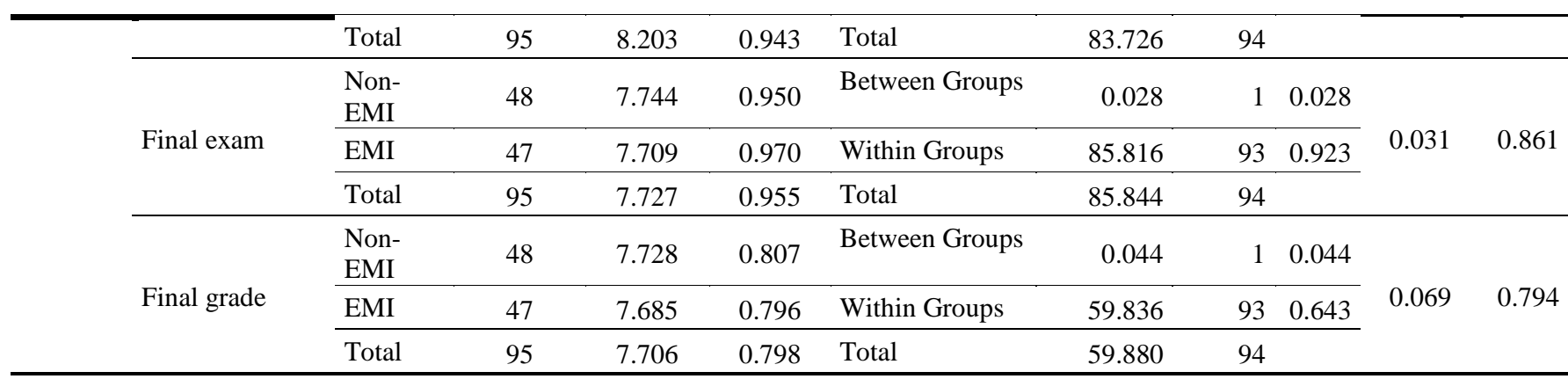

${ }^{1}$ Camacho-Miñano, M. \& Rivero Menéndez, M.J. (2010). Introducción a la contabilidad financiera. Madrid: Ed. Pearson (Spanish version). Camacho-Miñano, M.., Akpinar, M.; Rivero, M.J.; Urquia, E. \& Eskola, A. (2012). Beyond figures: Introduction to Financial accounting. Madrid: Ed. Anaya (English version).

2 This scale is to be understood as follows: students with grades ranging between 9-10 are outstanding or A; students between 7-8.9 are very good or B; students between 5-6.9 are pass or C, and, finally, students between $0-4.9$ are failed or D.

3 The university entrance exam in Spain (or 'selectividad') is taken after students finish their upper secondary school studies and is compulsory to apply for higher education. The exam is offered twice a year (June or September), depending on when students complete their studies. The purpose of this exam is to check their level of maturity and knowledge. The grade obtained in this exam, together with students' record, often conditions their chances to enrol in a specific degree. In the case of Business Administration the cut-off grade has ranged between 6 and 6.5 in the last 5 years).

${ }^{4}$ However, this does not mean, as the literature clearly indicates (see Barwell, 2009; Tatzl \& Messnarz, 2013), that mathematics is language free. On the contrary, what we are stressing here is the importance of reading skills and the mastery of technical mathematical registers for effective text comprehension and problem-solving tasks. 